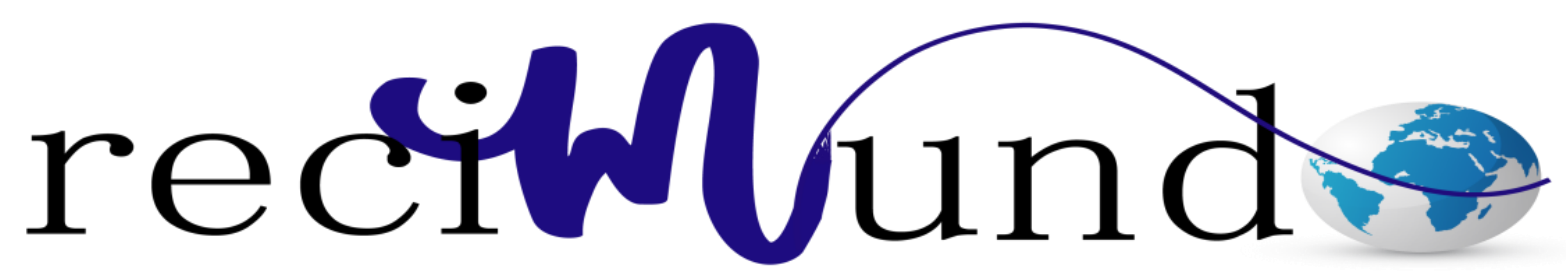

Revista Cientifica Mundo de la Investigación y el Conocimiento

Karen Yazmith Guerrero Loaiza ${ }^{\text {a }}$ T Tatiana Carolina Campoverde Larreta ${ }^{\text {b}}$; María Fernanda Baquerizo Godoy ${ }^{c}$; María Salomé Medina Medina ${ }^{d}$

Tratamiento del herpes genital

Genital herpes treatment

Revista Científica Mundo de la Investigación y el Conocimiento. Vol. 3 núm.3, septiembre, ISSN: 2588-073X, 2019, pp. 824-841

DOI: $10.26820 /$ recimundo/3.(3).septiembre.2019.824-841

URL: http://recimundo.com/index.php/es/article/view/551

Código UNESCO: 3205 Medicina Interna

Tipo de Investigación: Artículo de Revisión

Editorial Saberes del Conocimiento

Recibido: $15 / 05 / 2019$

Aceptado: 23/06/2019

Publicado: 30/09/2019

Correspondencia: karen.guerrero@outlook.com

a. Master Universitario en Dirección y Gestión Sanitaria; Médico; Investigador Independiente; Guayaquil, Ecuador; karen.guerrero@outlook.com

b. Médico; Investigador Independiente; Guayaquil, Ecuador; taty-carolina@ hotmail.com

c. Médico; Investigador Independiente; Guayaquil, Ecuador; maferbaquerizo86@ gmail.com

d. Médico; Investigador Independiente; Guayaquil, Ecuador; bunnyraven@ hotmail.com 


\section{Tratamiento del herpes genital}

Vol. 3, núm. 3., (2019)

Karen Yazmith Guerrero Loaiza; Tatiana Carolina Campoverde Larreta; María Fernanda Baquerizo Godoy; María Salomé Medina Medina

\section{RESUMEN}

El herpes es causado por el virus del herpes simple (VHS). El VHS-1 causa infecciones orofaciales y genitales. El VHS-2 causa principalmente infecciones genitales. En los EE. UU. VHS-1 es más frecuente que el VHS-2, y VHS-2 es predominante entre afroamericanos y mujeres. La infección inicial por VHS a menudo es subclínica. La replicación viral ocurre en ganglios, el virus se propaga a otras superficies mucosas a través de los nervios sensoriales periféricos. La manifestación clínica incluye, infección de la piel y la mucosa, herpes orofacial, herpes genital, panadizo herpético, encefalitis herpética, herpes neonatal adquirido en el momento del parto, aunque es raro pero grave y queratitis herpética. Las pruebas de diagnóstico incluyen cultivo, detección de anticuerpos, biopsia de piel y prueba de proteína $\mathrm{C}$ reactiva (PCR) para detectar la presencia de ADN viral. Se recomienda tratamiento anestésico tópico para aliviar la picazón y el dolor y los medicamentos antivirales como aciclovir, valaciclivir y famiciclovir. El antiviral también se recomienda para la terapia supresora del herpes durante los últimos meses de embarazo. Los brotes recurrentes son comunes y varían entre individuos; sin embargo la genética desempeña un papel importante en la frecuencia de los brotes de herpes labial. El desarrollo de un medicamento para bloquear el microARN cuyo trabajo es suprimir VHS-1 en latencia, puede prevenir los brotes.

Palabras Claves: Herpes; Virus del Herpes Simple (VHS); VHS-1; VHS-2; Manejo y pronóstico. 


\title{
Tratamiento del herpes genital
}

Vol. 3, núm. 3., (2019)

Karen Yazmith Guerrero Loaiza; Tatiana Carolina Campoverde Larreta; María Fernanda Baquerizo Godoy; María Salomé Medina Medina

\begin{abstract}
Herpes is caused by the herpes simplex virus (HSV). HSV-1 causes orofacial and genital infections. HSV-2 mainly causes genital infections. In the USA UU. HSV-1 is more frequent than HSV-2, and HSV-2 is predominant among African-Americans and women. The initial HSV infection is often subclinical. Viral replication occurs in ganglia, the virus spreads to other mucous surfaces through peripheral sensory nerves. The clinical manifestation includes infection of the skin and mucosa, orofacial herpes, genital herpes, herpetic whitlow, herpetic encephalitis, neonatal herpes acquired at the time of delivery, although it is rare but serious and herpetic keratitis. Diagnostic tests include culture, antibody detection, skin biopsy and C-reactive protein (PCR) test to detect the presence of viral DNA. Topical anesthetic treatment is recommended to relieve itching and pain and antiviral medications such as acyclovir, valaciclivir and famiciclovir. The antiviral is also recommended for herpes suppressive therapy during the last months of pregnancy. Recurrent outbreaks are common and vary among individuals; However, genetics play an important role in the frequency of outbreaks of cold sores. The development of a drug to block the microRNA whose job is to suppress HSV-1 in latency, can prevent outbreaks.
\end{abstract}

Key Words: Herpes; Herpes Simplex Virus (HSV); HSV-1; HSV-2; Management and Prognosis. 


\section{Tratamiento del herpes genital}

Vol. 3, núm. 3., (2019)

Karen Yazmith Guerrero Loaiza; Tatiana Carolina Campoverde Larreta; María Fernanda Baquerizo Godoy; María Salomé Medina Medina

\section{Introducción.}

Los virus del herpes simple tienen distribución mundial y se encuentran en las poblaciones de humanos más remotas. Las tasas mundiales de VHS-1 o VHS-2 están entre 60 y 95\% en adultos siendo más común el VHS-1 que VHS-2, con tasas que aumentan a medida que las personas envejecen. Las tasas de VHS-1 son entre $70 \%$ y $80 \%$ en poblaciones de bajo nivel socioeconómico y $40 \%$ a $60 \%$ en poblaciones de mejor nivel socioeconómico. (Mertz, Trees, \& Levine, 2008)

Los autores (Looker, Garnett, \& Schmid, 2008) en su estudio expresan que la prevalencia de VHS-2 en personas de entre 15 y 50 años es de aproximadamente 535 millones a partir de 2003 o el 16\% de la población, con tasas más altas en África subsahariana y más bajas en Europa occidental, y con tasas más altas entre las mujeres y las del mundo en desarrollo. En los EE. UU, el $57.7 \%$ de la población está infectada con VHS-1 y 16.2\% están infectados con VHS-2, y la prevalencia de VHS-2 fue $39.2 \%$ en negros y $20.9 \%$ en mujeres.

La infección por herpes es la causa predominante de úlceras genitales en todo el mundo, con aumento de uso de PCR para la detección de infección por VHS. El VHS-1 causa principalmente boca, garganta, cara, ojo e infecciones del sistema nervioso central, mientras que VHS-2 causa principalmente infecciones anogenitales. Sin embargo, cada uno puede causar infecciones en todas las áreas. (Chayavichitsilp, Buckwalter, Krakowski, \& AC, 2009)

La infección por VHS se contrae por contacto directo con una lesión o cuerpo activo líquido de una persona infectada. Las presentaciones clínicas de VHS incluyen infección de piel 


\section{Tratamiento del herpes genital}

Vol. 3, núm. 3., (2019)

Karen Yazmith Guerrero Loaiza; Tatiana Carolina Campoverde Larreta; María Fernanda Baquerizo Godoy; María Salomé Medina Medina

y mucosa, orofacial herpes, herpes genital, blanco herpético, encefalitis herpética, déficits cognitivos del trastorno bipolar y Enfermedad de Alzheimer. (Dickerson \& Borrow, 2012)

Para su diagnóstico se emplea la prueba por detección de anticuerpos contra VHS por PCR, y el nuevo Immunodot. Sin embargo, la prueba de glucoproteína específica de G (IgG) es más del 98\% específica para discriminar VHS-1 de VHS- 2. El manejo con medicamentos antivirales puede reducir la frecuencia de esta patología y la anestesia tópica se recomienda para aliviar la picazón y dolor, así como también, la prevención mediante barreras como el condón y el uso de agentes antivirales.

De tal manera, la preocupación acerca del padecimiento de este tipo de infecciones conlleva al autor a realizar una revisión bibliográfica que sea de utilidad respecto a la fisiopatología y manejo de infecciones por herpes simple.

\section{Métodos y materiales.}

Para el desarrollo de este proceso investigativo, se plantea como metodología la encaminada hacia una orientación científica particular que se encuentra determinada por la necesidad de indagar en forma precisa y coherente una situación, en tal sentido (Davila, 2015) define la metodología "como aquellos pasos previos que son seleccionados por el investigador para lograr resultados favorables que le ayuden a plantear nuevas ideas". (p.66)

Lo citado por el autor, lleva a entender que el desarrollo de la acción investigativa busca simplemente coordinar acciones enmarcadas en una revisión bibliográfica con el fin de 


\section{Tratamiento del herpes genital}

Vol. 3, núm. 3., (2019)

Karen Yazmith Guerrero Loaiza; Tatiana Carolina Campoverde Larreta; María Fernanda Baquerizo Godoy; María Salomé Medina Medina

complementar ideas previas relacionadas Tratamiento del herpes genital, a través de una revisión de literatura, para así finalmente elaborar un cuerpo de consideraciones generales que ayuden a ampliar el interés propuesto.

\section{Tipo de Investigación}

Dentro de toda práctica investigativa, se precisan acciones de carácter metodológico mediante las cuales, se logra conocer y proyectar los eventos posibles que la determinan, así como las características que hacen del acto científico un proceso interactivo ajustado a una realidad posible de ser interpretada. En este sentido, se puede decir, que la presente investigación corresponde al tipo documental, definido por Castro (2016), "se ocupa del estudio de problemas planteados a nivel teórico, la información requerida para abordarlos se encuentra básicamente en materiales impresos, audiovisuales y /o electrónicos”. (p.41).

En consideración a esta definición, la orientación metodológica permitió la oportunidad de cumplir con una serie de actividades inherentes a la revisión y lectura de diversos documentos donde se encontraron ideas explicitas relacionadas con los tópicos encargados de identificar a cada característica insertada en el estudio. Por lo tanto, se realizaron continuas interpretaciones con el claro propósito de revisar aquellas apreciaciones o investigaciones propuestas por diferentes investigadores relacionadas con el tema de interés, para luego dar la respectiva argumentación a los planteamientos, en función a las necesidades encontradas en la indagación. 


\section{Tratamiento del herpes genital}

Vol. 3, núm. 3., (2019)

Karen Yazmith Guerrero Loaiza; Tatiana Carolina Campoverde Larreta; María Fernanda Baquerizo Godoy; María Salomé Medina Medina

\section{Fuentes Documentales}

El análisis correspondiente a las características que predomina en el tema seleccionado, llevan a incluir diferentes fuentes documentales encargadas de darle el respectivo apoyo y en ese sentido cumplir con la valoración de los hechos a fin de generar nuevos criterios que sirven de referencia a otros procesos investigativos. Para (CASTRO, 2016) las fuentes documentales incorporadas en la investigación documental o bibliográfica, "representa la suma de materiales sistemáticos que son revisados en forma rigurosa y profunda para llegar a un análisis del fenómeno".(p.41). Por lo tanto, se procedió a cumplir con la realización de una lectura previa determinada para encontrar aquellos aspectos estrechamente vinculados con el tema, con el fin de explicar mediante un desarrollo las respectivas apreciaciones generales de importancia.

\section{Técnicas para la Recolección de la Información}

La conducción de la investigación para ser realizada en función a las particularidades que determinan a los estudios documentales, tiene como fin el desarrollo de un conjunto de acciones encargadas de llevar a la selección de técnicas estrechamente vinculadas con las características del estudio. En tal sentido, (Bolívar, 2015), refiere, que es "una técnica particular para aportar ayuda a los procedimientos de selección de las ideas primarias y secundarias”. (p. 71).

Por ello, se procedió a la utilización del subrayado, resúmenes, fichaje, como parte básica para la revisión y selección de los documentos que presentan el contenido teórico. Es decir, que mediante la aplicación de estas técnicas se pudo llegar a recoger informaciones en cuanto a la revisión bibliográfica de los diversos elementos encargados de orientar el proceso de investigación. Tal como lo expresa, (Bolívar, 2015) "las técnicas documentales proporcionan las 


\section{Tratamiento del herpes genital}

Vol. 3, núm. 3., (2019)

Karen Yazmith Guerrero Loaiza; Tatiana Carolina Campoverde Larreta; María Fernanda Baquerizo Godoy; María Salomé Medina Medina

herramientas esenciales y determinantes para responder a los objetivos formulados y llegar a resultados efectivos" (p. 58). Es decir, para responder con eficiencia a las necesidades investigativas, se introdujeron como técnica de recolección el método inductivo, que hizo posible llevar a cabo una valoración de los hechos de forma particular para llegar a la explicación desde una visión general.

Asimismo, se emplearon las técnicas de análisis de información para la realización de la investigación que fue ejecutada bajo la dinámica de aplicar diversos elementos encargados de determinar el camino a recorrer por el estudio, según, (Bolívar, 2015) las técnicas de procesamiento de datos en los estudios documentales "son las encargadas de ofrecer al investigador la visión o pasos que debe cumplir durante su ejercicio, cada una de ellas debe estar en correspondencia con el nivel a emplear" (p. 123). Esto indica, que para llevar a cabo el procesamiento de los datos obtenidos una vez aplicado las técnicas seleccionadas, tales como: fichas de resumen, textual, registros descriptivos entre otros, los mismos se deben ajustar al nivel que ha sido seleccionado.

\section{Resultados.}

\section{Transmisión}

(Lipschutz, 1921) inoculó materiales de lesiones herpéticas genitales en la piel de humanos, provocando infección clínica en 48 a 72 horas en seis personas y en 24 horas en un caso. Transmisión de HSV ocurre con mayor frecuencia a través del contacto cercano con una persona que está eliminando el virus en un sitio periférico, en la superficie de la mucosa o en las secreciones genitales u orales. La infección se produce por inoculación de virus en superficies de 


\section{Tratamiento del herpes genital}

Vol. 3, núm. 3., (2019)

Karen Yazmith Guerrero Loaiza; Tatiana Carolina Campoverde Larreta; María Fernanda Baquerizo Godoy; María Salomé Medina Medina

la mucosa (por ejemplo, orofaringe, cuello uterino, conjuntiva) o a través de pequeñas grietas en la piel. Debido a que HSV es inactivado fácilmente a temperatura ambiente y por secado, la propagación de aerosoles y fómites son medios inusuales de transmisión. La transmisión de HSV-1 por contacto urogenital se reconoce cada vez más, tal vez porque de una disminución en la prevalencia específica de HSV-1 por edad al comienzo de la actividad sexual.

\section{Propagación de HSV-1}

La infección por secreciones orales a otras áreas de la piel es un peligro de ciertas ocupaciones (por ejemplo, dentistas, cuidado respiratorio personal de la unidad), y brotes nosocomiales y adquiridos en laboratorio en personal hospitalario o de enfermería han sido reportado. Se reconocen brotes entre luchadores, la transmisión de HSV puede ocurrir en bebés nacidos de madre que excreta HSV en el momento del parto. Las infecciones anales y perianales con HSV-1 o HSV-2 son comunes entre poblaciones sexualmente activas de HSH (hombres sexo con hombres). La mayoría de los casos ocurre dentro de los 5 días de contacto, destacando el corto período de incubación de la infección primaria (Qunin, Corey, \& Chatfee, 1981).

Para la infección por VIH, una relación clara entre la carga viral de VIH genital y plasmática y el riesgo por coito de la transmisión del VIH se establece. Sin embargo, debido a que los niveles genitales de HSV-2 fluctúan rápidamente con el tiempo, el grado en que la carga viral de la pareja fuente durante el sexo afecta la probabilidad de transmisión es desconocido. La eliminación subclínica o asintomática del VIH en las secreciones orales y genitales es común incluso en personas inmunocompetentes, y la transmisión ocurre más comúnmente durante el desprendimiento asintomático. 


\section{Tratamiento del herpes genital}

Vol. 3, núm. 3., (2019)

Karen Yazmith Guerrero Loaiza; Tatiana Carolina Campoverde Larreta; María Fernanda Baquerizo Godoy; María Salomé Medina Medina

La frecuencia de desprendimiento detectable notablemente heterogénea entre aquellos seropositivos con HSV-2, lo que sugiere que la transmisión por coito puede ser altamente dependiente del socio fuente. Un estudio de modelación predijo que un grupo central de "súper spreaders" con altas tasas de reactivación puede representar una cantidad desproporcionadamente grande porcentaje de nuevas infecciones (Blower, Wald, \& Gershengorn, 2004).

\section{Fisiopatología}

La exposición al HSV en las superficies mucosas o en los sitios de piel desgastada permite la entrada del virus y el inicio de su replicación en las células de la epidermis y la dermis. La infección inicial por HSV es a menudo subclínica, sin lesiones aparentes. En modelos animales y sujetos humanos, tanto la adquisición clínica como la adquisición subclínica son asociado con suficiente replicación viral para permitir la infección del nervio sensorial o autónomo terminaciones. Después de atravesar la brecha neuroepitelial y entrar en la célula neuronal, el virus o, más probablemente la nucleocápside se transporta intraaxonalmente a los cuerpos de las células nerviosas en los ganglios.

Para la infección por HSV-1, los ganglios del trigémino se infectan con mayor frecuencia, aunque también se produce la extensión a los ganglios cervicales inferiores y superiores. Con la infección genital, los ganglios de la raíz del nervio sacro (S2 a S5) se ven afectados con mayor frecuencia. En humanos, se desconoce el intervalo desde la inoculación del virus al tejido periférico para extenderse a los ganglios (Baringer, 1974).

La replicación viral ocurre en los ganglios y el tejido neural contagioso durante la infección primaria solamente. Después de la inoculación inicial del ganglio neural, el virus se 


\section{Tratamiento del herpes genital}

Vol. 3, núm. 3., (2019)

Karen Yazmith Guerrero Loaiza; Tatiana Carolina Campoverde Larreta; María Fernanda Baquerizo Godoy; María Salomé Medina Medina

propaga a otras superficies de la piel de la mucosa por migración centrífuga de viriones infecciosos a través de nervios sensoriales periféricos. Este modo de propagación explica las características de desarrollo de nuevas lesiones distantes del cultivo inicial de vesículas en pacientes con genitales primarios e infección orofacial por HSV, la gran área de superficie sobre la cual se pueden visualizar estas vesículas y la recuperación del virus del tejido neural distante de las neuronas que inervan la inoculación. La propagación contagiosa del virus también puede tener lugar mediante autoinoculación y permitir una mayor extensión de la enfermedad. La viremia está presente durante aproximadamente el 25\% de las infecciones primarias por HSV-2, y su presencia puede afectar la historia natural de la enfermedad por HSV-2 en términos de sitio, gravedad y frecuencia de reactivación. Estudios recientes sugieren que la tasa de reactivación es mucho mayor frecuente y dinámico de lo previamente reconocido (Mark, Wald, \& Margaret, 2008). El uso de hisopos de PCR anogenitales diarios mostró que la tasa media de desprendimiento del $95 \%$ de los pacientes con un anticuerpo HSV-2 positivo que eliminó el virus es del $25 \%$ de los días, con un amplio rango de variabilidad de interpretación (rango, 2\% a 75\%). Los estudios clínicos demuestran que el huésped también influye en la reactivación. Los pacientes inmunocomprometidos tienen una enfermedad más grave.

Los anticuerpos que se desarrollan después de una infección inicial con el tipo de HSV evitan la reinfección con el mismo tipo de virus: una persona con antecedentes de infección orofacial causada por HSV-1 no puede contraer herpes o una infección genital causada por HSV1. En una pareja monógama, una mujer seronegativa corre más del $30 \%$ por año riesgo de contraer una infección por HSV de un compañero masculino seropositivo. Si una infección oral por HSV-1 es contraído primero, la seroconversión habrá ocurrido después de 6 semanas para 


\section{Tratamiento del herpes genital}

Vol. 3, núm. 3., (2019)

Karen Yazmith Guerrero Loaiza; Tatiana Carolina Campoverde Larreta; María Fernanda Baquerizo Godoy; María Salomé Medina Medina

proporcionar anticuerpos protectores contra una futura infección por HSV-1. El herpes simple es un virus de ADN bicatenario (Mertz G. , 1993).

\section{Manifestación clínica}

La infección por HSV causa varios trastornos médicos distintos. La infección común de la piel o la mucosa puede afectar la cara y la boca (herpes orofacial), genitales (herpes genital) o manos (panadizo herpético). Los trastornos ocurren cuando el virus infecta y daña los ojos (queratitis herpética) o invade el sistema nervioso central dañando el cerebro (encefalitis herpética). Personas con sistemas inmunes inmaduros o suprimidos, como los recién nacidos, los receptores de trasplantes o las personas con SIDA son propensos a sufrir complicaciones graves por las infecciones por HSV. La infección por HSV también se ha asociado con un déficit cognitivo del trastorno bipolar y la enfermedad de Alzheimer, aunque esto a menudo depende de la genética de la persona infectada (Parker \& Nye, 1925).

En todos los casos, el sistema inmunitario nunca eliminó el HSV del cuerpo. Después de una infección primaria, el virus ingresa en el sitio de la infección primaria, migra al cuerpo celular de la neurona y se vuelve latente en el ganglio. Como resultado de una infección primaria; el cuerpo produce anticuerpos contra un tipo particular de HSV involucrado, prevenir una infección posterior de ese tipo en un sitio diferente. En individuos infectados con HSV-1, seroconversión después de una infección oral previene infecciones adicionales por HSV-1, como el panadizo, el herpes genital y el herpes del ojo. Muchas personas infectadas con HSV-2 no muestran síntomas físicos, individuos sin los síntomas se describen como herpes asintomático o subclínico. 


\section{Tratamiento del herpes genital}

Vol. 3, núm. 3., (2019)

Karen Yazmith Guerrero Loaiza; Tatiana Carolina Campoverde Larreta; María Fernanda Baquerizo Godoy; María Salomé Medina Medina

El herpes simple neonatal es una infección por HSV en un bebé. Es una condición rara pero grave, generalmente causada por la transmisión vertical de (HSV-1o 2) de la madre al recién nacido. Durante la inmunodeficiencia, herpes simple puede causar lesiones inusuales en la piel. Una de las más llamativas es la aparición de erosiones lineales limpias en pliegues de la piel, con apariencia de corte con cuchillo. La sicosis herpética es recurrente o infección de herpes simple inicial que afecta principalmente a los folículos pilosos. El eccema herpético es una infección por el virus del herpes con la dermatitis atópica crónica puede provocar la propagación del herpes simple a través de las áreas eccematosas (James \& Berger, 2006).

La causa de la parálisis de Bell, un tipo de parálisis facial, se desconoce, puede estar relacionada con la reactivación de $\mathrm{HSV}-1$, sin embargo, la teoría ha sido cuestionada, ya que el HSV se detecta en un gran número de personas que nunca han experimentado parálisis facial y niveles más altos de anticuerpos para HSV no se encuentran en individuos infectados con HSV con la parálisis de Bell en comparación con aquellos sin.

\section{Diagnóstico}

El herpes orofacial primario se identifica fácilmente mediante un examen clínico de personas sin antecedentes de lesiones y contacto con un individuo con infección por HSV-1 conocida. La apariencia y distribución de llagas en estos individuos generalmente se presenta como úlceras orales múltiples, redondas y superficiales acompañadas de gingivitis aguda. El herpes genital puede ser más difícil de diagnosticar que el herpes oral, ya que las personas infectadas con HSV-2 no tienen síntomas clásicos. Las pruebas de laboratorio incluyen cultivo 


\section{Tratamiento del herpes genital}

Vol. 3, núm. 3., (2019)

Karen Yazmith Guerrero Loaiza; Tatiana Carolina Campoverde Larreta; María Fernanda Baquerizo Godoy; María Salomé Medina Medina

del virus, anticuerpo fluorescente directo (DFA), estudios para dirigir el virus, la biopsia de piel y la prueba de reacción en cadena de la polimerasa para detectar la presencia de ADN viral. La confirmación permite la subtipificación del virus, lo que puede ayudar a predecir la frecuencia de reactivación después del primer episodio de infección oral o genital por VHS, sitio de infección del SNC y probabilidad de resistencia a los medicamentos.

Hasta hace poco, las pruebas serológicas para detectar anticuerpos contra el VHS rara vez fueron útiles para el diagnóstico y no se utilizaron habitualmente en la práctica clínica. El ensayo serológico $\operatorname{IgM}$ anterior no podía diferenciar entre los anticuerpos generados en respuesta a infección por HSV-1 o HSV-2. Sin embargo, la nueva prueba de HSV inmune glucoproteína G específica (IgG) es más que 98\% específico para discriminar HSV-1 de HSV-2 (Ashley, 1988). Algunos profesionales médicos modernos creen que la nueva IgG siempre debe preferirse clínicamente a la antigua prueba de IgM, pero no todos los médicos parecen estar informados de la disponibilidad la prueba de IgG más nueva y confiable.

\section{Manejo y terapia}

Ningún método erradica el virus del herpes del cuerpo, pero los medicamentos antivirales pueden reducir la frecuencia, duración y gravedad de los brotes. Los analgésicos como el ibuprofeno y el paracetamol (acetaminofeno) pueden reducir dolor y fiebre El tratamiento anestésico tópico como prilocaína, lidocaína, benzocaína o tetracaína también puede aliviar la picazón y el dolor. Varios medicamentos antivirales son efectivos para tratar el herpes, incluidos el aciclovir y el valaciclovir, famiciclovir y penpenciclovir. La evidencia apoya el uso de 


\section{Tratamiento del herpes genital}

Vol. 3, núm. 3., (2019)

Karen Yazmith Guerrero Loaiza; Tatiana Carolina Campoverde Larreta; María Fernanda Baquerizo Godoy; María Salomé Medina Medina

aciclovir y valaciclovir en el tratamiento del herpes labial, así como infecciones por herpes en personas con cáncer. Numerosos ensayos de aciclovir en infecciones mucocutáneas por HSV se han realizado huéspedes inmunocompetentes e inmunosuprimidos (Wald, Carrel, Remington, \& M., 2002). Famciclovir, la formulación oral penciclovir, también es clínicamente efectivo en el tratamiento de una variedad de infecciones por HSV-1 y HSV-2. Valacylovir es un éster valílico de aciclovir que tiene mayor biodisponibilidad. Una serie de antivirales tópicos son eficaces para el herpes labial, incluidos el ciclovir, el penciclovir y el docosano.

Se afirma que ciertos medicamentos alternativos (complementarios) son beneficiosos en el tratamiento del herpes que incluyen equinácea, eleutro, L-lisina, zinc, productos de monolaurina de abeja y andallovera, la evidencia es insuficiente aun para apoyar el uso de muchos de estos compuestos.

\section{Prevención y pronóstico}

Al igual que con casi todas las infecciones de transmisión sexual, las mujeres son más susceptibles a adquirir HSV-2 que los hombres. Anualmente, sin el uso de antivirales o condones, el riesgo de transmisión del VHS-2 del hombre infectado a la mujer es de aproximadamente 8-11\% (Kulhanjian \& Soroush, 1992). Esto se cree que se debe a la mayor exposición de tejido mucoso a posibles sitios de infección. El riesgo de transmisión de mujeres infectadas a hombres es de alrededor del 4-5\% anualmente. La terapia antiviral supresora reduce 


\section{Tratamiento del herpes genital}

Vol. 3, núm. 3., (2019)

Karen Yazmith Guerrero Loaiza; Tatiana Carolina Campoverde Larreta; María Fernanda Baquerizo Godoy; María Salomé Medina Medina

estos riesgos en un 50\%. Los antivirales también ayudan a prevenir desarrollo de HSV sintomático en escenarios de infección, lo que significa que la pareja infectada será seropositiva pero sin síntomas en alrededor del 50\%. El uso de condón también reduce significativamente el riesgo de transmisión. El uso de condón es mucho más eficaz para prevenir la transmisión de hombre a mujer que viceversa. Los efectos de combinar el uso de antivirales y condones es más o menos aditivo, lo que resulta en una reducción combinada del $75 \%$ en la transmisión anual riesgo. La infección previa por HSV-1 parece reducir el riesgo de adquirir infección por HSV-2 en mujeres por factor de tres (Mertz, Trees, \& Levine, 2008). Sin embargo, los portadores asintomáticos del HSV-2 siguen siendo contagiosos.

Algunos individuos asintomáticos no son conscientes de su infección, se los considera en alto riesgo de propagar HSV. Cuando uno de la pareja tiene infección por herpes simple y otras no, el uso de medicamentos antivirales, como valaciclovir, en conjunto con un condón, disminuye aún más las posibilidades de transmisión a la pareja no infectada.

\section{Conclusiones.}

Se ha realizado una amplia investigación sobre las vacunas para la prevención y el tratamiento de las infecciones por herpes. Se han realizado ensayos clínicos sin éxito para las vacunas de la subunidad de glucoproteína. Para terapia, solo una vacuna HSV competente en replicación se ha sometido a pruebas, una propuesta de vacuna competente requiere más prueba con animales. Investigadores han creado una ribozima cabeza de martillo que se dirige y corta el ARNm de genes esenciales en HSV-1. El martillo, que se dirige al ARNm del gen UL20, redujo 


\section{Tratamiento del herpes genital}

Vol. 3, núm. 3., (2019)

Karen Yazmith Guerrero Loaiza; Tatiana Carolina Campoverde Larreta; María Fernanda Baquerizo Godoy; María Salomé Medina Medina

enormemente el nivel de infección ocular por HSV-1 en conejos y redujo el rendimiento viral in vivo, pero se sigue investigando antes de que pueda intentarse en personas infectadas con herpes.

Las infecciones por el virus del herpes simple (VHS) son frecuentes en todo el mundo. El VHS-1 causa principalmente infecciones en la boca, garganta, infecciones de la cara, los ojos y el sistema nervioso central, HSV-2 causa principalmente infecciones genitales. Brotes recurrentes son comunes especialmente entre personas inmunosuprimidas. La prevención se lleva a cabo principalmente mediante el uso de condones y medicamentos antivirales.

\section{Bibliografía.}

Ashley, R. (1988). Comparison of Western blot(immunodot) and glycoprotein G-specific immunodot enzyme assay for the detection antibodies to herpes simplex virus type 1 and type 2 in human sera. JClin Microbiol, 662-7.

Baringer, J. (1974). Recovery of herpes simplex virus from human sacral ganglion. $N$ Engl $J$ Med, 828-30.

Blower, S., Wald, A., \& Gershengorn, H. (2004). Targetingvirological core groups: a new paradigm for comtrolling herpes simples virus type 2 epidemic. $J$ Infect Dis, 1610-17.

Bolívar, J. (2015). Investigación Documental. México. Pax.

Castro, J. (2016). Técnicas Documentales. México. Limusa.

Chayavichitsilp, P., Buckwalter, J., Krakowski, \& AC. (2009). Herpessimplex. PediatrRev., 11929.

Davila, A. (2015). Diccionario de Términos Científicos. . Caracas: Editorial Oasis.

Dickerson, F., \& Borrow, J. (2012). La infección con el virus del herpes simple tipo 1 se asocia con un déficit cognitivo en el trastorno bipolar. . Psycholtry Biol., 88-93.

James, W., \& Berger, T. (2006). Diseases of the Skin clinical Dermatology. Saunders Elsevier.

Kulhanjian, J., \& Soroush, V. (1992). Identification of women at unsuspected risk of primary infection with herpes virus type 2 during pregnancy. N Engl J Med., 916-20. 


\section{Tratamiento del herpes genital}

Vol. 3, núm. 3., (2019)

Karen Yazmith Guerrero Loaiza; Tatiana Carolina Campoverde Larreta; María Fernanda

Baquerizo Godoy; María Salomé Medina Medina

Lipschutz, B. (1921). Untersuchungenuber die Aetologie der Krankheiten der Herpes Gruppe(herpes zoster genitalis. Herpes fibrillis)ArchDermatolSymp, 136-428.

Looker, K., Garnett, G., \& Schmid, G. (7 de 6 de 2008). An estimate of the global prevalence and incidence of herpes simplex virus type 2 infection. Recuperado el 9 de 23 de 2019, de https://www.who.int/bulletin/volumes/86/10/07-046128/en/

Mark, K., Wald, A., \& Margaret, A. (2008). Rapidly cleared episode of herpes simplex virus reactivation in immunocompetent adults. J Infect Dis., 1141-49.

Mertz, G. (1993). Epidemiology of genital herpes infections. Infect Dis Clin NorthAm, 825-39.

Mertz, K., Trees, D., \& Levine, W. (2008). Etiología de las úlceras gentitales y prevalencia de la coinfección por el virus de la inmunodeficiencia humana en 10 ciudades de EE. UU. El Grupo de Vigilancia de la Enfermedad de las Úlceras Genitales. 58-95.

Parker, F., \& Nye, R. (1925). Studies on filterable viruses. Cultivation of herpes virus. Am JPathol., 1-37.

Qunin, T., Corey, L., \& Chatfee, R. (1981). The etiology of anorectal infection in homosexual men. Am J Med, 395-406.

Wald, A., Carrel, D., Remington, \& M. (2002). .Two day regimen of acyclovir for treatment of recurrent genital herpes simplex virus type 2 infection. Clin Infect Dis, 944-48. 